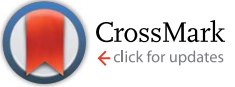

Cite this: RSC Adv., 2017, 7, 861

Received 31st October 2016 Accepted 18th November 2016

DOI: $10.1039 / c 6 r a 26084 e$

www.rsc.org/advances

\section{Interdigitated crystalline MMT-MCA in polyamide 6}

\author{
Min Zhao, ${ }^{a}$ Deqi Yi, ${ }^{\star a}$ Giovanni Camino, ${ }^{b}$ Alberto Frache ${ }^{b}$ and Rongjie Yang ${ }^{a}$
}

Polyamide 6 (PA6) was flame retarded by using interdigitated crystalline montmorillonite-melamine cyanurate (MMT-MCA). Its morphologies were assessed by using X-ray diffraction (XRD), transmission electron microscopy (TEM) and scanning electron microscopy (SEM), thermal stability by thermogravimetric analysis (TGA), fire retardancy by limiting oxygen index (LOI), vertical burning testing (UL-94), and cone calorimeter (CONE) tests and mechanical properties by stress strain tests. The results indicated that the interdigitated crystalline MMT-MCA was homogeneously nano-dispersed as MMT and MCA in PA6 due to a $\pi-\pi$ stacking exfoliation mechanism. Compared with PA6/MCA and PA6/OMMT/MCA, PA6/MMT-MCA shows enhanced thermal stability and fire retardancy. With 8 wt\% total loading of MMTMCA, the sample of PA6/MMT-MCA reached UL-94 V-0 rating $(3.2 \mathrm{~mm})$. The MMT-MCA can also enhance the mechanical properties of PA6.

\section{Introduction}

Polymer/clay nanocomposites $(\mathrm{PCNs})^{1-6}$ have attracted great academic and industrial interest over recent decades due to enhanced mechanical ${ }^{7,8}$ and gas barrier properties, ${ }^{\mathbf{9 , 1 0}}$ and fire retardancy, ${ }^{11,12}$ at low particle loadings and simple polymer recycling. ${ }^{13}$ The properties are all quite dependent on the dispersion. If the clay is not dispersed at the nanometer level, the enhanced properties that are usually observed are not seen. As to clays, montmorillonite (MMT) is the most conveniently used one, ${ }^{14-16}$ which belongs to the family of $2: 1$ phyllosilicates. Its crystal structure consists of stacked layers made of two silica tetrahedrons fused to an edge-shared octahedral sheet of alumina. The layer thickness is $\sim 0.98 \mathrm{~nm}$ and the lateral dimensions may vary from $300 \mathrm{~nm}$ to several microns, giving an aspect ratio greater than 1000 . The adjacent layers are separated by a regular van der Waals gap, which is referred to as interlayer or gallery. Isomorphic substitution within the layers generates negative charges that are normally counterbalanced by sodium or calcium ions. The use of clays as such, greatly limits the class of miscible polymers only to hydrophilic ones, e.g. poly(ethylene oxide) and poly(vinyl alcohol). To overcome this restriction the silicate surface is modified by exchanging the inorganic cations initially present in the interlayer space, with organic cationic surfactants, mainly different kinds of "onium" salts. ${ }^{\mathbf{1 7 - 1 9}}$ Sometimes, electroneutral organic molecules can also be used for the organic modification. The principal rule for the

\footnotetext{
${ }^{a}$ National Engineering Research Center of Flame Retardant Materials, School of Materials Science and Engineering, Beijing Institute of Technology, No. 5 South Zhongguancun Street, Haidian District, Beijing, 10081, China. E-mail: Yidq@bit. edu.cn; Fax: +86-010-68913066; Tel: +86-010-68913066

${ }^{b}$ Polytechnic of Turin, UdR INSTM of Turin, Alessandria Campus, V.le Teresa Michel 5, 15121 Alessandria, Italy
}

modification is that the long aliphatic tails of organic modifiers make the interlayer space organophilic and can give a larger interlayer spacing. ${ }^{\mathbf{2 0 , 2 1}}$

At present, there are principally four experimentally established strategies for fabricating PCNs. (1) intercalation of polymer from solution; (2) in situ intercalative polymerization; (3) template synthesis; (4) melt intercalation. This last, is the simplest and most economically favorable method for industrial applications in the light of costs reduction. But the dispersion of clay is still limited by using the melt blending approach. The dispersing ability still remains challenging.

We have found that by using melamine cyanurate (MCA) as electroneutral organophilic intercalated guest, MMT dispersion in polyamide 6 is strongly improved. Melamine cyanurate is a crystalline complex which is much similar to graphite. ${ }^{22}$ Both MCA and graphite contain an atom thick 2D sheet stacked via additional weak quadrupole/quadrupole interaction, ${ }^{23,24}$ which is called $\pi-\pi$ stacking. ${ }^{25-27}$ This weak interaction allows for layers sliding so that graphite is used as a lubricant and graphene can be separated from graphite using tip stick exfoliation. ${ }^{\mathbf{2 8 2 9}}$ At variance with graphene, the MCA single layer is formed by $1: 1$ melamine and cyanuric acid molecules selfassembling by inter molecular hydrogen bonds ${ }^{30,31}$ and there are also relatively weak van der Waals interactions between neighboring molecules, which makes the $\pi-\pi$ MCA interlayer interaction weaker than in graphene. MCA which has higher thermal stability and lower toxicity compared with MA and CA, is an important nitrogen-containing fire retardant, ${ }^{32}$ widely used for example in polyamide, ${ }^{33,34}$ and polyurethanes..$^{35}$

In our previous work, ${ }^{36}$ a novel intercalated nanocomposite was synthesized, by inserting the electroneutral MCA atom thick sheets within the MMT galleries by $\pi-\pi$ stacking mechanism, producing an interdigitated crystalline structure, named MMT-MCA. Two types of interdigitated structures were 
prepared: a well-ordered one to one MMT-MCA alternated structure with one layer MCA in between two MMT layers and another with multiple MCA layers insertion between two MMT layers with controllable MCA layers thickness to over $100 \mathrm{~nm}$.

In this work, a novel nano-material is prepared by meltblending MMT-MCA and polyamide 6 to make nanocomposites. Their morphologies, MMT layers dispersion, thermal properties and flammability are investigated and compared with materials obtained by MCA and organically modified MMT (OMMT) melt blending. Due to the novel $\pi-\pi$ stacking exfoliation mechanism, MMT-MCA shows excellent MMT inorganic layers dispersion in the PA6 matrix enhancing its properties and fire retardancy.

\section{Experimental section}

\subsection{Materials}

The interdigitated crystalline Montmorillonite-melamine cyanurate (MMT-MCA) nano-material was synthesized in our laboratory, by the method published in previous work. ${ }^{36}$ Polyamide 6 (PA6, B30S) with a melting point of $224{ }^{\circ} \mathrm{C}$ and a melt flow index of $110 \mathrm{~g} / 10 \mathrm{~min}\left(260{ }^{\circ} \mathrm{C} / 5 \mathrm{~kg}\right)$ was obtained from Bayer AG. Organic montmorillonite (OMMT, I.24TL) with a $d_{001}$ spacing of $1.65 \mathrm{~nm}$ was purchased from Nanocor Inc. Melamine cyanurate (MCA) was received from Sichuan Fine Chemistry Institute, China. All the chemicals were used as received without any further purification. The simulated structure of MMT-MCA is shown in Scheme 1.

\subsection{Preparation of PA6/MMT-MCA nanocomposites}

PA6/MMT-MCA nanocomposites were prepared by melt blending and extrusion in a twin-screw extruder ( $\mathrm{SHJ}-20)$ with a screw length/diameter ratio of 20 , according to the formulations in Table 1. The temperatures of the sections were 230, 233, $235,237,235$ and $230{ }^{\circ} \mathrm{C}$. The test specimens were prepared by using an injection molding machine (HTF80X1) at
Table 1 Formulations of PA6/MMT-MCA nanocomposites

\begin{tabular}{lllll}
\hline Samples & $\begin{array}{l}\text { PA6 } \\
(\mathrm{wt} \%)\end{array}$ & $\begin{array}{l}\text { MMT-MCA } \\
(\mathrm{wt} \%)\end{array}$ & $\begin{array}{l}\text { OMMT } \\
\text { (wt\%) }\end{array}$ & $\begin{array}{l}\text { MCA } \\
\text { (wt\%) }\end{array}$ \\
\hline PA6 & 100 & 0 & 0 & 0 \\
PA6/MCA & 92 & 0 & 0 & 8 \\
PA6/MMT-MCA ${ }^{a}$ & 92 & 8 & 0 & 0 \\
PA6/OMMT/MCA & 92 & 0 & 1.6 & 6.4
\end{tabular}

${ }^{a}$ In MMT-MCA, the weight ratio of MCA is $80 \%$.

a temperature of $230-240{ }^{\circ} \mathrm{C}$. All of the additives and PA6 were fed at the same time after uniformly mixing.

\subsection{Characterization}

The XRD patterns were obtained using a Rigaku Miniflex II desktop X-ray diffractometer with a $\mathrm{Cu}(\mathrm{K} \alpha)$ source, $\lambda=1.54078$ $\AA$. The samples were scanned in the $2 \theta$ range of $2-10^{\circ}$ with step size of $0.02^{\circ}$ and scanning rate of $2^{\circ} \mathrm{min}^{-1}$.

The morphologies of the PA6 samples were characterized by transmission electron microscope (TEM, JEM-2100) on cryogenic microtomed samples using a Leica EM FC7. The cryofractured sections of liquid nitrogen frozen PA6 specimens and char residues obtained from cone calorimeter tests were examined with Hitachi ultra-high resolution S4800 field emission scanning electron microscope (SEM).

Thermo-gravimetric analysis (TGA) was performed on a Netzsch 209 F1 thermal analyzer under a $50 \mathrm{~mL} \mathrm{~min}{ }^{-1}$ nitrogen flowing atmosphere at a heating rate of $10{ }^{\circ} \mathrm{C} \mathrm{min}^{-1}$ from 40 to $800{ }^{\circ} \mathrm{C}$.

The limiting oxygen index (LOI) value was measured by using an FTA II oxygen index meter (Rheometric Scientific Ltd., U.K.) with specimen dimensions of $130.0 \times 6.5 \times 3.0 \mathrm{~mm}^{3}$ according to ASTM D 2863-97.

The UL 94 vertical burning test was conducted on a CZF-5Atype instrument (Jiangning Analysis Instrument Company,

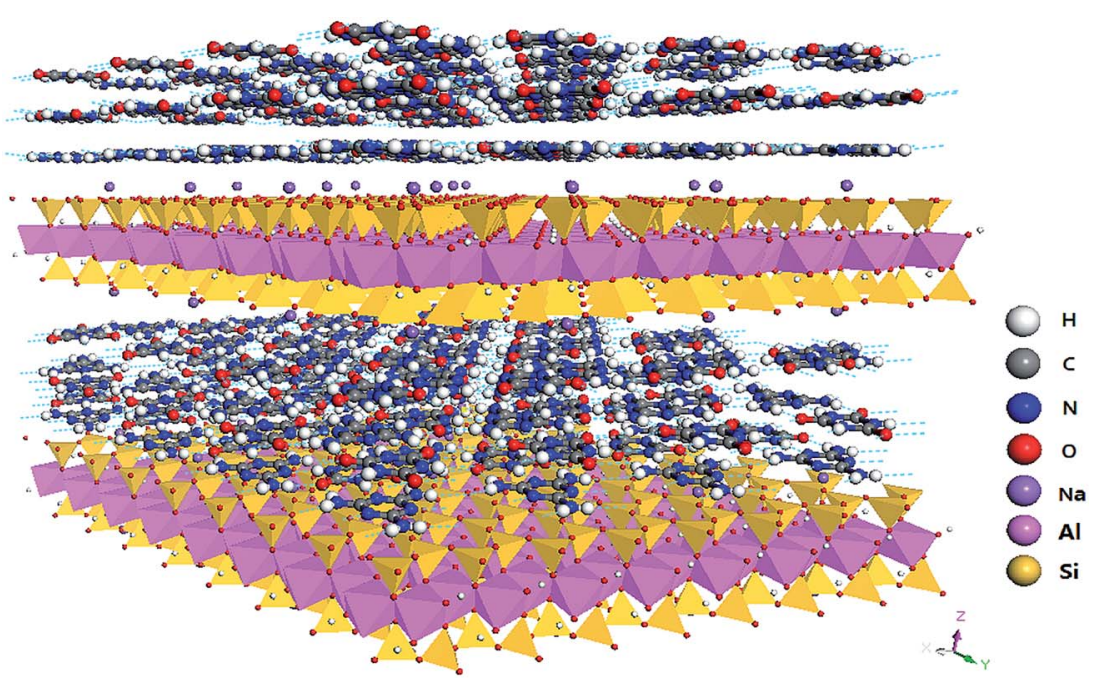

Scheme 1 The simulated interdigitated crystalline structure of MMT-MCA. 


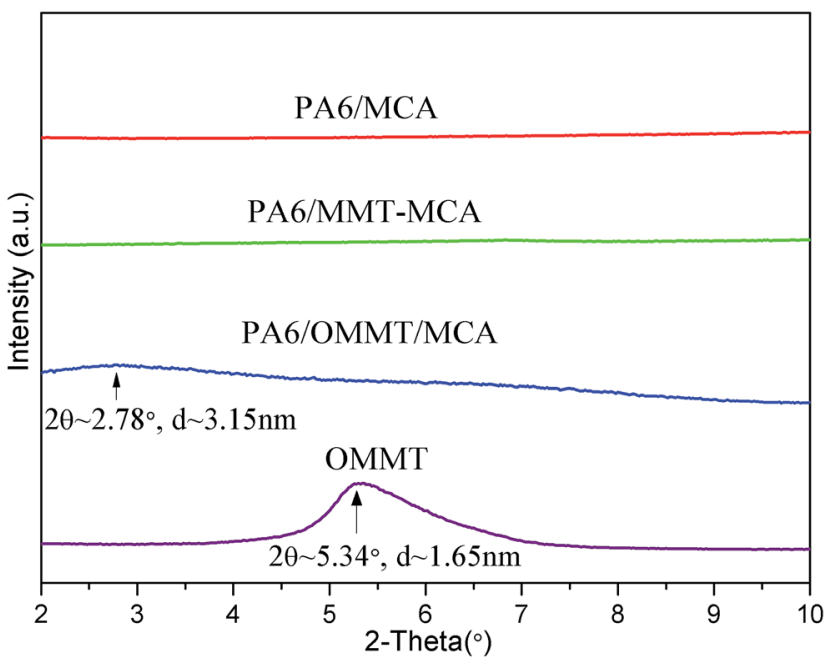

Fig. 1 XRD traces of the PA6 samples and OMMT

China) with specimen dimensions of $130.0 \times 13.0 \times 3.0 \mathrm{~mm}^{3}$ according to the America National UL-94 test ASTM D 3801.

The cone calorimeter (CONE) experiments were performed on a fire testing technology apparatus (FTT) with specimen dimensions of $100.0 \times 100.0 \times 3.0 \mathrm{~mm}^{3}$ at a heat flux of $50 \mathrm{~kW}$ $\mathrm{m}^{-2}$ according to ASTM E 1354-10. The specimens were measured horizontally without any grids. All the samples were tested in triplicate. The cone results are reproducible to within about $\pm 10 \%$.
The mechanical properties were conducted at room temperature of $25{ }^{\circ} \mathrm{C} \pm 2{ }^{\circ} \mathrm{C}$ on a universal testing machine (CMT-410 4, MTS Systems (China) Co., Ltd.) with a cross-head

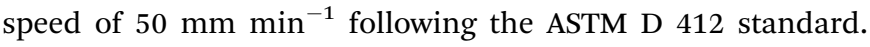
The tensile strength, elongation at break and Young's modulus were evaluated.

\section{Results and discussion}

\subsection{Morphologies of PA6/MMT-MCA nanocomposites}

Fig. 1 shows the XRD traces of PA6 samples with $8 \%$ of previously-synthesized MMT-MCA (PA6/MMT-MCA) or MCA 8\% (PA6/MCA) or OMMT 1.6\% + MCA 6.4\%, (PA6/OMMT/MCA) and OMMT.

The XRD trace of PA6/MMT-MCA shows no peaks between 2 and $10^{\circ}$, indicating that MMT is exfoliated in PA6 matrix. The XRD trace of PA6/OMMT/MCA shows a broadened peak at about $3.15 \mathrm{~nm}$ interlayer distance with $2 \theta$ value around $2.78^{\circ}$, while for OMMT the peak is at $1.65 \mathrm{~nm}$ with $2 \theta$ value around $5.34^{\circ}$ pointing at a strongly disordered structure of MMT layers.

Further evidence for dispersion of clay can be observed in the TEM images. Fig. 2a displays a TEM image of PA6/MMT-MCA and shows exfoliated silicate layers due to $\pi-\pi$ stacking exfoliation mechanism. The TEM image for PA6/OMMT/MCA (Fig. 2b) confirmed that a mixed morphology has formed in PA6 matrix, where most of the silicate layers were exfoliated except few clusters of black lines, which reveal the presence of some intercalated stacks of MMT lamellas. Thus, PA6/OMMT/
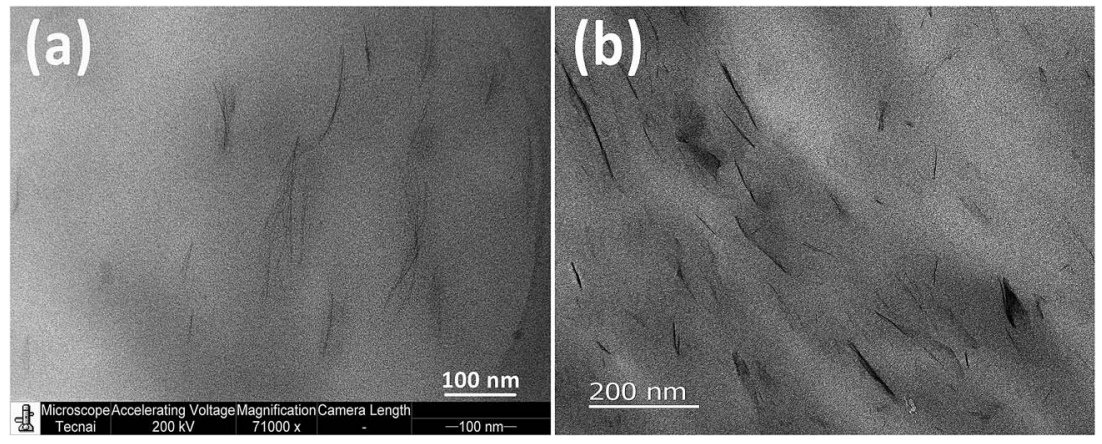

Fig. 2 TEM images of PA6/MMT-MCA (a) and PA6/OMMT/MCA (b).
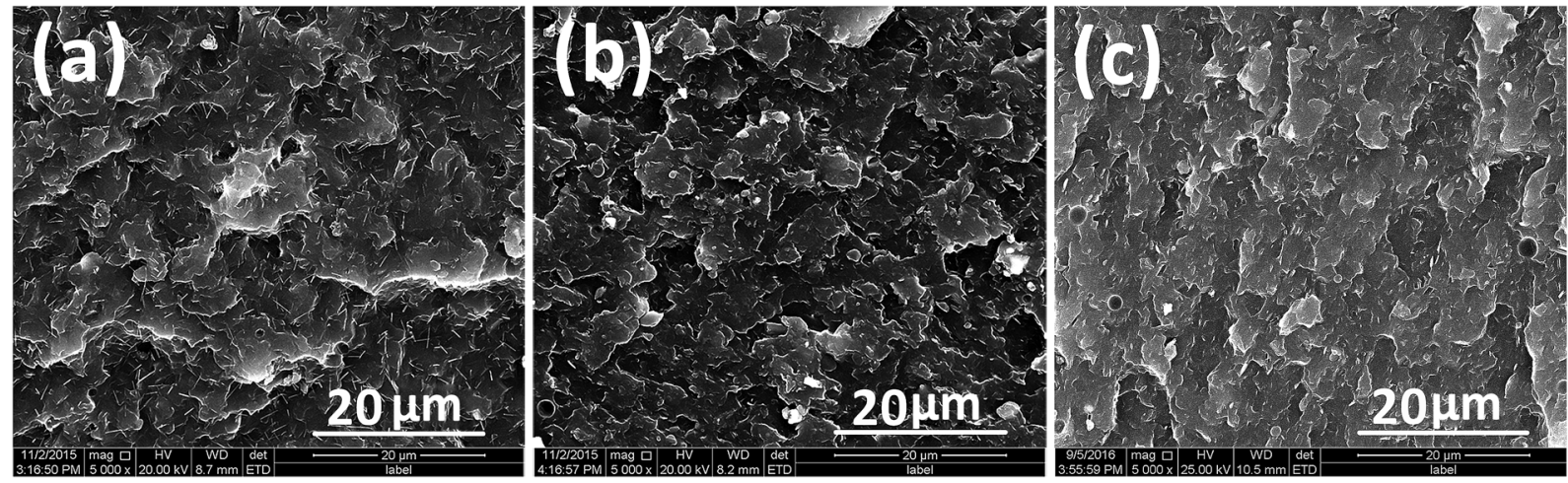

Fig. 3 SEM micrographs of the brittle fracture surface of PA6/MCA (a), PA6/MMT-MCA (b) and PA6/OMMT/MCA (c). 


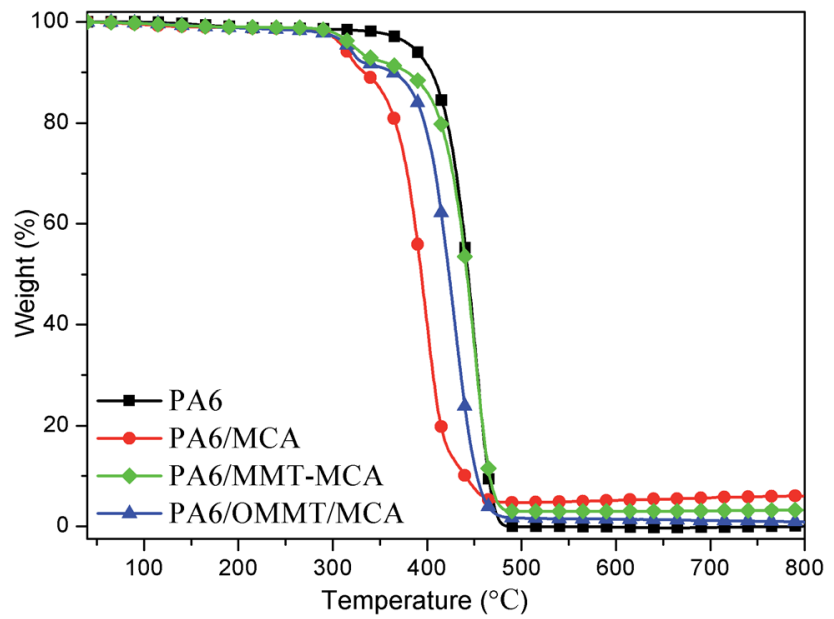

Fig. 4 TGA curves of PA6 samples in the nitrogen atmosphere.

Table $2 T_{5 \%}, T_{\max 1}, T_{\max 2}$, and residues of PA6 samples

\begin{tabular}{lllll}
\hline Samples & & & & Residues at \\
\hline PA6 & 392 & 450 & - & 0.02 \\
PA6/MCA & 312 & 318 & 400 & 6.03 \\
PA6/MMT-MCA & 323 & 326 & 450 & 3.26 \\
PA6/OMMT/MCA & 318 & 320 & 430 & 1.62
\end{tabular}

MCA can be described as a mixed intercalated-exfoliated structure.

No peak was found in PA6/MCA in the XRD trace between 2 and $10^{\circ}$. Since MCA is a hydrogen bonding based complex and susceptible to TEM electrons impact, it's also hard to obtain TEM images of MCA in PA6. Then we did the SEM test for brittle fracture surface in the following results to see the distribution of MCA in PA6 matrix.

In order to investigate the effect of interdigitated crystalline MMT-MCA on the compatibility in the PA6 matrix, the microstructure of the brittle fracture surface of PA6 samples was observed by SEM. As shown in Fig. 3, the micrographs were taken at $5000 \times$ magnification to represent the general surface of the fracture section.

In both PA6/OMMT/MCA and PA6/MCA, MCA is uniformly dispersed in PA6 matrix as fibers with a length of 5-10 $\mu \mathrm{m}$ and nano thick. Whereas, PA6/MMT-MCA shows a uniform structure in which MCA needles are absent owing to a molecular dispersion favoured by the molecular interaction with exfoliated MMT layers. Clearly, the introduction of MMT-MCA leads to a large interfacial contact between MMT-MCA and PA6 matrix.

\subsection{Thermal stability}

To study the influence of interdigitated crystalline MMT-MCA on the thermal degradation behavior of PA6, TGA was carried out. Fig. 4 gives the TGA curves of the PA6 samples in a nitrogen atmosphere. The mass loss at $5 \mathrm{wt} \%$ degradation $\left(T_{5 \%}\right)$, taken as the onset temperature of the degradation, maximum mass loss rate temperature $\left(T_{\max 1}\right.$ and $\left.T_{\max 2}\right)$ obtained from the DTG curves, and the fraction of the residues remaining at $800{ }^{\circ} \mathrm{C}$, char, are listed in Table 2.

As revealed in Fig. 4 and Table 2, PA6 exhibits one step degradation process, its $T_{5 \%}$ is $392{ }^{\circ} \mathrm{C}$, and $T_{\max }$ is $450{ }^{\circ} \mathrm{C}$. The thermal degradation processes of PA6/MCA, PA6/MMT-MCA and PA6/OMMT/MCA show two stages. The first stage occurs between 300 and $350{ }^{\circ} \mathrm{C}$. The second stage occurs between 350 and $500{ }^{\circ} \mathrm{C}$ with a rapid mass loss. Compared with PA6, PA6/ MCA has the lowest onset temperature $\left(T_{5 \%}\right)$ at $312{ }^{\circ} \mathrm{C}$ and $T_{\max 2}$ at $400{ }^{\circ} \mathrm{C}$ owing to accelerated thermal degradation of PA by interaction between PA6 and melamine and cyanuric acid from MCA thermal degradation. ${ }^{37}$ PA6/MMT-MCA and PA6/ OMMT/MCA have onset temperature at about $323{ }^{\circ} \mathrm{C}$ and $318{ }^{\circ} \mathrm{C}$, which is higher than PA6/MCA by $12{ }^{\circ} \mathrm{C}$ and $6{ }^{\circ} \mathrm{C}$, respectively, probably owing to inhibited interaction between PA6 and MCA in presence of MMT. ${ }^{37}$

Compared with PA6/MCA, $T_{\max 2}$ of PA6/MMT-MCA and PA6/ OMMT/MCA are significantly increased about $50{ }^{\circ} \mathrm{C}$ and $30{ }^{\circ} \mathrm{C}$, respectively. It is clear that the combination of MMT can result in better barrier properties of the nanocomposites and thus responsible for the enhanced thermal stability than PA6/MCA. The residue of PA6/MMT-MCA is decreased from $6.03 \%$ in PA6/MCA to $3.26 \%$, the PA6/OMMT/MCA has the lowest residue at $1.62 \%$. The above results indicate that the thermal stability of PA6 samples can be significantly differentiated with the dispersion of clay or without clay. While, compared with PA6/ MCA and PA6/OMMT/MCA, PA6/MMT-MCA shows enhanced thermal stability.

\subsection{Flame retardancy of PA6 samples}

LOI and UL-94 are most useful bench scale tests to evaluate the flame retardancy of materials. The results of PA6 samples are

Table 3 The LOI and UL-94 tests results of PA6 samples

\begin{tabular}{|c|c|c|c|c|c|c|c|}
\hline Samples & LOI (\%) & UL-94 (3.2 mm) & $t_{1}^{a}(\mathrm{~s})$ & $t_{2}^{b}(\mathrm{~s})$ & Flame to clamp & Dripping & Cotton ignition \\
\hline PA6 & 23.5 & NA & $>30$ & $>30$ & Yes & Yes & Yes \\
\hline PA6/MMT-MCA & 25.1 & $\mathrm{~V}-0$ & 2.1 & 2.0 & No & No & No \\
\hline PA6/MCA & 24.6 & $\mathrm{~V}-2$ & 6.5 & 3.5 & No & Yes & Yes \\
\hline PA6/OMMT/MCA & 22.2 & $\mathrm{~V}-2$ & 9.7 & 2.3 & No & Yes & Yes \\
\hline
\end{tabular}

${ }^{a}$ Afterflame time after first ignition. ${ }^{b}$ Afterflame time after second ignition. 

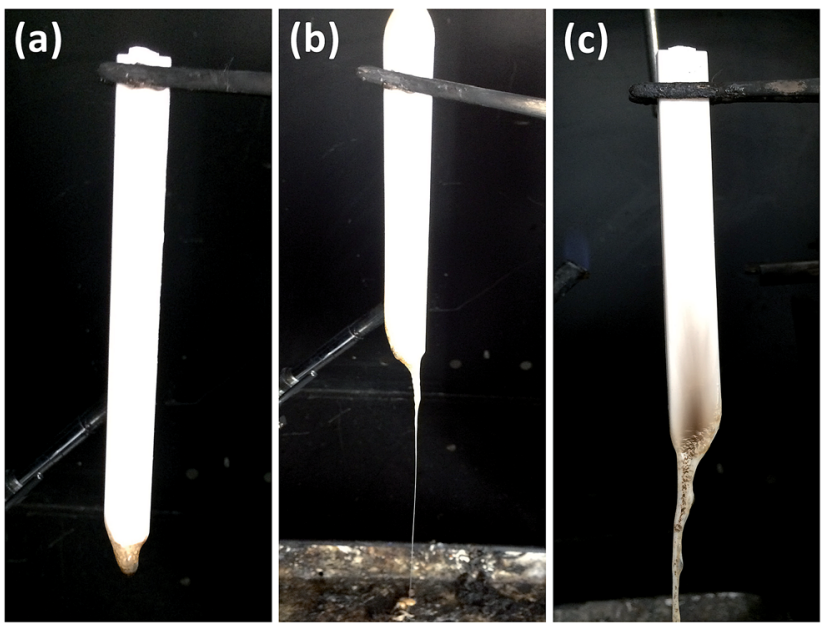

Fig. 5 Digital photos of the residues of PA6 samples after UL-94 test: PA6/MMT-MCA (a); PA6/MCA (b); PA6/OMMT/MCA (c).

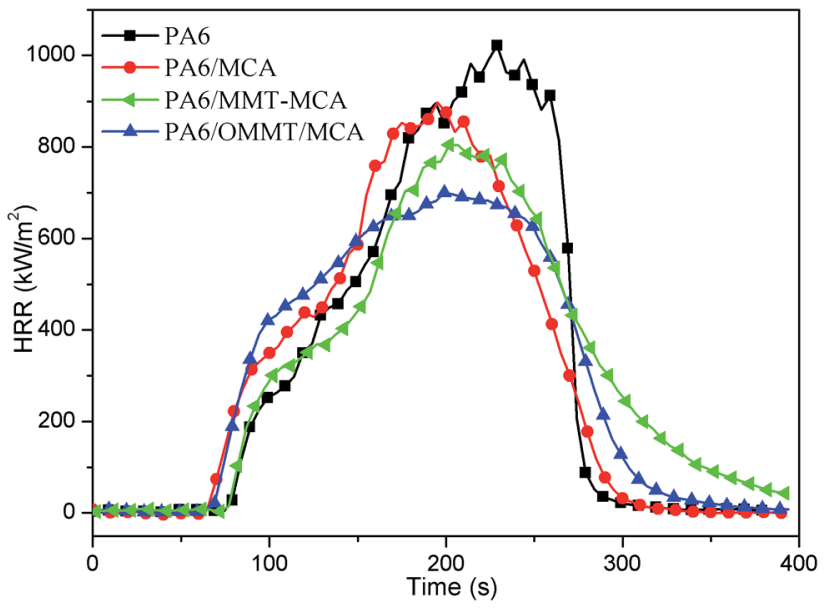

Fig. 6 Heat release rate (HRR) curves of PA6 samples.

summarized in Table 3 and their digital photos during the UL94 test are shown in Fig. 5.

The LOI of PA6, PA6/MCA, PA6/MMT-MCA and PA6/OMMT/ MCA are $23.5 \%, 24.6 \%, 25.1 \%$ and $22.2 \%$, respectively. Compared with PA6, both PA6/MMT-MCA and PA6/MCA slightly increased, and PA6/MMT-MCA has the highest LOI value. While the LOI value of PA6/OMMT/MCA decreased to $22.2 \%$.

To pass UL-94 vertical test, afterflame time and flammable dripping should be controlled. MCA is one useful flame retardant for PA6, but usually over $10 \%$ loading of MCA is necessary to help PA6 pass UL-94 test V-0 rating. In here, all PA6 samples have the same total loading at $8 \mathrm{wt} \%$. The PA6/MCA and PA6/OMMT/MCA samples can only pass V-2 rating due to excessive afterflame time and dripping. Afterflame time of PA6/ MMT-MCA is significantly decreased and no dripping was observed during the test, indicating PA6/MMT-MCA reached UL-94 V-0 rating $(3.2 \mathrm{~mm})$.

From the results of the LOI and UL-94 tests, it is clear that MMT-MCA shows outstanding fire retardancy in PA6 due to optimised nano-dispersion, which provides barrier, increases the viscosity of the melting PA6 and suppresses dripping.

\subsection{Cone calorimetric studies}

Cone calorimetry is one of the most effective bench-scale approaches to evaluate the combustion behaviour of materials. The main parameters obtained by the cone calorimetry test are: time to ignition (TTI); heat release rate (HRR), and especially its peak value (PHRR); total heat released (THR); total smoke release (TSR). Heat release rate (HRR) curves are presented in Fig. 6 and all of cone calorimetric data for PA6 samples are collected in Table 4 .

In cone calorimeter, the ignition occurs when an ignitable mixture of air and combustible gases arising from the thermal degradation of the samples has been formed. It seems, therefore, that in the first stages of combustion, the earlier mass loss shown by nanocomposite in TGA, compared to PA6, lowers ignition time and gives a higher initial HRR compared with the neat polymer. This behavior is quite typical for nanocomposites and it is usually ascribed to the release of volatiles evolved by the decomposition of clay surfactant. In here, both PA6/MCA and PA6/OMMT/MCA show decreased TTI compared with neat PA6. While PA6/MMT-MCA shows same TTI with neat PA6, which is one further proof for ignition behavior.

The HRR curve for neat PA6 exhibits a sharp peak, which may be attributed to the rapid destruction of formed char by the external radiation, indicating that PA6 burns fiercely during combustion. The remaining PA6 matrix continued burning, and resulting in a relatively high HRR value (1021.8 $\mathrm{kW} \mathrm{m}{ }^{-2}$ ) which is reduced by $7.7 \%$ by $8 \mathrm{wt} \%$ MCA addition. Compared with neat PA6, in PA6 nanocomposites, the PHRR of PA6 nanocomposites is decreased. The reduction of PHRR of PA6/MMT-MCA and PA6/OMMT/MCA is $17.4 \%$ and $30.3 \%$, respectively. While the TSR of PA6/MMT-MCA and PA6/ OMMT/MCA are also decreased. And PA6/OMMT/MCA has the lowest TSR value. As a result of these observation, MMT could function as barriers and has excellent smoke

Table 4 Cone calorimetry data of PA6 samples

\begin{tabular}{|c|c|c|c|c|c|}
\hline Samples & TTI (s) & $\operatorname{PHRR}\left(\mathrm{kW} \mathrm{m}^{-2}\right)$ & Reduction of PHRR (\%) & THR (MJ m ${ }^{-2}$ ) & $\operatorname{TSR}\left(\mathrm{m}^{2} \mathrm{~s}^{-1}\right)$ \\
\hline PA6 & $74.8 \pm 6.5$ & $1021.8 \pm 40.1$ & - & $127.6 \pm 1.2$ & $867.7 \pm 20.1$ \\
\hline PA6/MMT-MCA & $74.5 \pm 2.5$ & $844.4 \pm 39.4$ & 17.4 & $126.5 \pm 0.4$ & $737.9 \pm 3.6$ \\
\hline PA6/OMMT/MCA & $63.3 \pm 1.2$ & $711.8 \pm 23.9$ & 30.3 & $122.9 \pm 0.8$ & $454.3 \pm 20.6$ \\
\hline
\end{tabular}




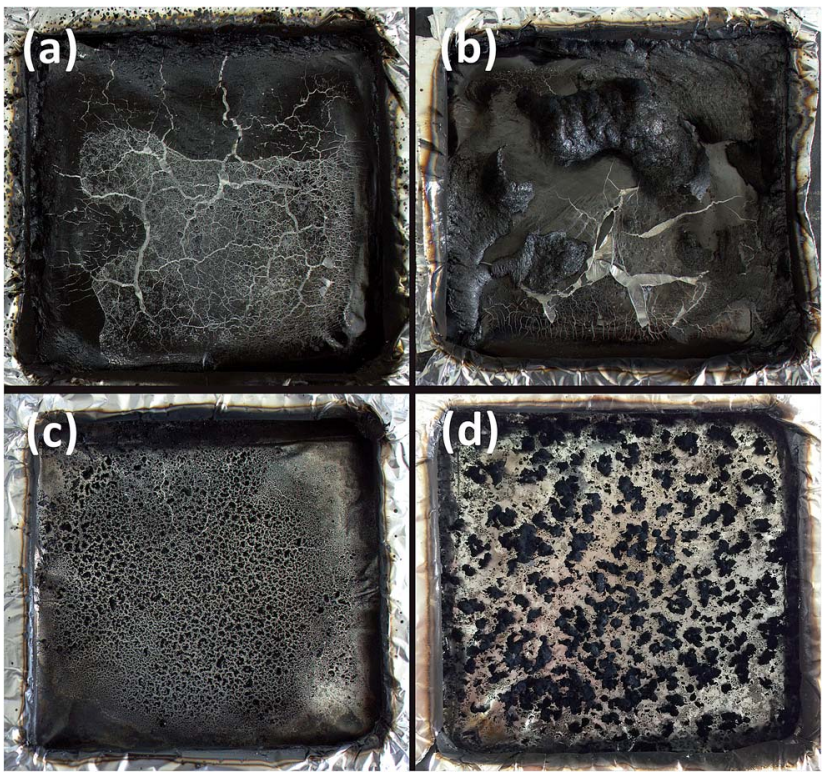

Fig. 7 Photographs of char residues for PA6 samples after cone calorimetry test: PA6 (a); PA6/MCA (b); PA6/MMT-MCA (c); and PA6/ OMMT/MCA (d).

suppression ability in the nanocomposites and thus lead to satisfactory performance. The presence of MMT does not affect the THR values too much. The THR values are relatively constant for all the PA6 samples.

\subsection{Char structure}

The char photographs of PA6 samples after cone calorimetry test are as shown in Fig. 7. All four PA6 samples did not show too much char residue. Scarce char is found with PA6, PA6/MCA shows thin char films, PA6/MMT-MCA shows a homogeneously distribution char structure, while PA6/OMMT/MCA has separated island char structure.

Further char structure information were observed using SEM as shown in Fig. 8. The char of PA6/MCA is a very thin and transparent film due to the char formation between interaction between PA6 and MCA. PA6/OMMT/MCA shows a cheese like char structure with smooth tube wall. The char of PA6/MMTMCA can be clearly separated into surface and interior: the surface char is a well-covered char film (Fig. 8a), which can perform barrier properties. While the interior char is a porous structure with circle layered rough microchannels (Fig. 8b), which probably undergo a procedure as shown in Fig. 9. The well-covered char film inhibits gas diffusion. Taking one bubble's movement into account, MMT and cross-linking char formation between PA6 and MCA increase melt viscosity, ${ }^{37-39}$ which decrease migration rate of gas bubble from inner to surface. The continuously generated gas increases the pressure and size of bubble. With the bubble moving to surface, a circle layered rough microchannel form. Rovenskaya's research points out that the rough microchannel can remarkable decrease gas flow rate. ${ }^{40}$ Therefore, well-covered char film and rough microchannel reduce diffusion and migration of flame gas, which leads to a prolonged time to ignition and modified
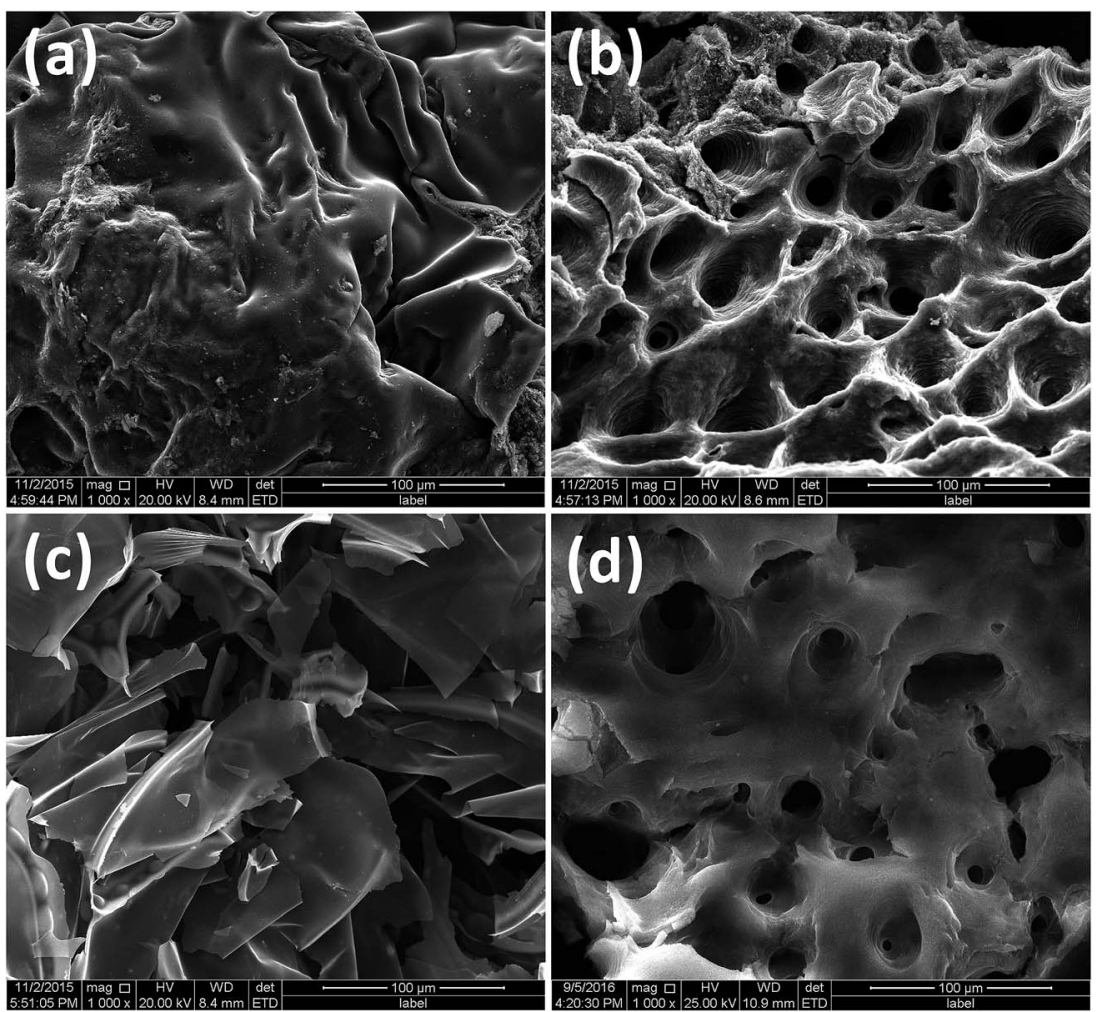

Fig. 8 SEM images of char residues for PA6 samples after cone calorimetry tests: exterior surface of PA6/MMT-MCA (a); and interior surface of PA6/MMT-MCA (b), PA6/MCA (c), and PA6/OMMT/MCA (d). 


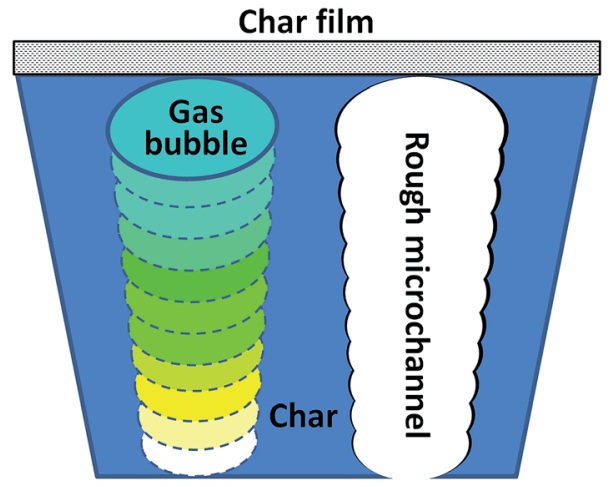

Fig. 9 Scheme of rough microchannel formation procedure.

Table 5 Mechanical properties of PA6 samples

\begin{tabular}{llll}
\hline Samples & $\begin{array}{l}\text { Tensile strength } \\
(\mathrm{MPa})\end{array}$ & $\begin{array}{l}\text { Elongation at } \\
\text { break }(\%)\end{array}$ & $\begin{array}{l}\text { Young's modulus } \\
(\mathrm{MPa})\end{array}$ \\
\hline PA6 & $64.8 \pm 0.7$ & $49.6 \pm 7.4$ & $1387.4 \pm 329.3$ \\
PA6/MCA & $50.9 \pm 0.5$ & $20.6 \pm 3.1$ & $424.5 \pm 75.9$ \\
PA6/MMT-MCA & $71.0 \pm 0.5$ & $22.4 \pm 2.8$ & $295.5 \pm 37.2$ \\
PA6/OMMT/MCA & $62.5 \pm 0.2$ & $14.4 \pm 2.0$ & $263.8 \pm 32.9$ \\
\hline
\end{tabular}

flame ability of PA6/MMT-MCA. While the porous char structure can limit movement of polymer chains, which leads increased melt viscosity of PA6 to play anti-dripping function.

\subsection{Mechanical properties}

The mechanical properties of the PA6 samples are listed in Table 5. The tensile strength, elongation at break and Young's modulus of pure PA6 are $64.8 \mathrm{MPa}, 49.6 \%$ and $1387.4 \mathrm{MPa}$, respectively. Owing to homogeneous nano-dispersion of MMTMCA in PA6, PA6/MMT-MCA shows the highest tensile strength at $71.0 \mathrm{MPa}$, which is $10 \%$ higher than pure PA6. In the addition of MCA, or OMMT and MCA, the tensile strength is decreased compared with pure PA6. PA6/MCA has the lowest tensile strength at 50.9 MPa due to the poor compatibility between PA6 and MCA. Compared with PA6, PA6/MCA, PA6/MMT-MCA and PA6/OMMT/MCA show a significant decrease in elongation at break and Young's modulus. Usually, polymer/clay nanocomposites can increase Young's modulus due to the uniformly dispersed silicate layers. ${ }^{41}$ So the PA6 samples show a decreased Young's modulus can be addressed to MCA.

\section{Conclusions}

In this work, a novel interdigitated crystalline MMT-MCA was incorporated into PA6 matrix. The presence of MMT-MCA improved the dual homogeneous dispersion in PA6 of MMT layers and MCA molecules owing to $\pi-\pi$ stacking mechanism of MCA in between two MMT layers. This mutual assistance in nanodispersion shows an increased contribution of MMT and MCA to PA6 fire retardance as compared to separate addition of MCA or OMMT and MCA. Indeed, MMT-MCA shows outstanding fire retardancy and prolonged TTI in PA6, which can help PA6 reach UL-94 V-0 rating $(3.2 \mathrm{~mm})$ with only $8 \mathrm{wt} \%$ loading of MMT-MCA due to nano-dispersion in PA6 and effective barrier and charring properties. Studies on the residual char show that a complete and well-covered char was formed, which protected the underlying polymer from further combustion during burning. The PA6/MMT-MCA also shows enhanced mechanical properties.

\section{Acknowledgements}

The work was partially financially supported by the National Natural Science Foundation of China under grant number 51303012, and the International Science \& Technology Cooperation Program of China under grant number 2014DFA52900, and the Nation High Technology Research and Development Program of China (863 Program) under grant number 2013AA032003.

\section{Notes and references}

1 P. Kiliaris and C. Papaspyrides, Polymer/layered silicate (clay) nanocomposites: an overview of flame retardancy, Prog. Polym. Sci., 2010, 35, 902-958.

2 H. Zhang, J. Zhang, R. Yun, Z. Jiang, H. Liu and D. Yan, Nanohybrids of organo-modified layered double hydroxides and polyurethanes with enhanced mechanical, damping and UV absorption properties, RSC Adv., 2016, 6, 3428834296.

3 H. W. P. Carvalho, C. V. Santilli, V. Briois and S. H. Pulcinelli, Polymer-clay nanocomposites thermal stability: experimental evidence of the radical trapping effect, RSC Adv., 2013, 3, 22830-22833.

$4 \mathrm{~J}$. L. Suter, D. Groen and P. V. Coveney, Mechanism of Exfoliation and Prediction of Materials Properties of ClayPolymer Nanocomposites from Multiscale Modeling, Nano Lett., 2015, 15, 8108-8113.

5 A. A. Stec, T. R. Hull, J. L. Torero, R. Carvel, G. Rein, S. Bourbigot, F. Samym, G. Camino, A. Fina and S. Nazare, Effects of fire retardants and nanofillers on the fire toxicity, ACS Symp. Ser., 2009, 1013, 342-366.

6 R. O. Mäkiniemi, P. Das, D. Hönders, K. Grygiel, D. Cordella, C. Detrembleur, J. Yuan and A. Walther, Conducting, SelfAssembled, Nacre-Mimetic Polymer/Clay Nanocomposites, ACS Appl. Mater. Interfaces, 2015, 7, 15681-15685.

7 P. Podsiadlo, A. K. Kaushik, E. M. Arruda, A. M. Waas, B. S. Shim, J. D. Xu, H. Nandivada, B. G. Pumplin, J. Lahann, A. Ramamoorthy and N. A. Kotov, Ultrastrong and stiff layered polymer nanocomposites, Science, 2007, 318, 80-83.

8 Y. Q. Rao and J. M. Pochan, Mechanics of Polymer-Clay Nanocomposites, Macromolecules, 2007, 40, 290-296.

9 E. H. Song, B. H. Kang, T. Y. Kim, H. J. Lee, Y. W. Park, Y. C. Kim and B. K. Ju, Highly Oriented Gold/NanoclayPolymer Nanocomposites for Flexible Gas Barrier Films, ACS Appl. Mater. Interfaces, 2015, 7, 4778-4783. 
10 Y. Cui, S. Kumar, B. Rao Kona and D. van Houcke, Gas barrier properties of polymer/clay nanocomposites, RSC Adv., 2015, 5, 63669-63690.

11 J. Zhu, A. B. Morgan, F. J. Lamelas and C. A. Wilkie, Fire properties of polystyrene-clay nanocomposites, Chem. Mater., 2001, 13, 3774-3780.

12 S.-B. Deng, W. Liao, J.-C. Yang, Z.-J. Cao and Y.-Z. Wang, Flame-Retardant and Smoke-Suppressed Silicone Foams with Chitosan-Based Nanocoatings, Ind. Eng. Chem. Res., 2016, 55, 7239-7248.

13 M. Si, T. Araki, H. Ade, A. Kilcoyne, R. Fisher, J. C. Sokolov and M. H. Rafailovich, Compatibilizing bulk polymer blends by using organoclays, Macromolecules, 2006, 39, 4793-4801.

14 H.-J. Sue, K. Gam, N. Bestaoui, N. Spurr and A. Clearfield, Epoxy nanocomposites based on the synthetic $\alpha$-zirconium phosphate layer structure, Chem. Mater., 2004, 16, 242-249.

15 M. C. Costache, M. J. Heidecker, E. Manias, G. Camino, A. Frache, G. Beyer, R. K. Gupta and C. A. Wilkie, The influence of carbon nanotubes, organically modified montmorillonites and layered double hydroxides on the thermal degradation and fire retardancy of polyethylene, ethylene-vinyl acetate copolymer and polystyrene, Polymer, 2007, 48, 6532-6545.

16 P. J. Wallis, A. L. Chaffee, W. P. Gates, A. F. Patti and J. L. Scott, Partial Exchange of Fe(III) Montmorillonite with Hexadecyltrimethylammonium Cation Increases Catalytic Activity for Hydrophobic Substrates, Langmuir, 2010, 26, 4258-4265.

17 G. Polizos, R. A. Vaia, H. Koerner and E. Manias, Dynamics of Amphiphilic Surfactants Confined in Montmorillonite Slits with Different Cation Exchange Capacities, J. Phys. Chem. B, 2013, 117, 13667-13678.

18 H. Heinz, R. A. Vaia, R. Krishnamoorti and B. L. Farmer, Self-Assembly of Alkylammonium Chains on Montmorillonite: Effect of Chain Length, Head Group Structure, and Cation Exchange Capacity, Chem. Mater., 2007, 19, 59-68.

19 K. Parida, G. B. B. Varadwaj, S. Sahu and P. C. Sahoo, Schiff Base Pt(II) Complex Intercalated Montmorillonite: A Robust Catalyst for Hydrogenation of Aromatic Nitro Compounds at Room Temperature, Ind. Eng. Chem. Res., 2011, 50, 78497856.

20 P. C. LeBaron, Z. Wang and T. J. Pinnavaia, Polymer-layered silicate nanocomposites: an overview, Appl. Clay Sci., 1999, 15, 11-29.

21 D. Yi, R. Yang and C. A. Wilkie, Layered double hydroxidemontmorillonite-a new nano-dimensional material, Polym. Adv. Technol., 2013, 24, 204-209.

22 S. Stankovich, D. A. Dikin, G. H. Dommett, K. M. Kohlhaas, E. J. Zimney, E. A. Stach, R. D. Piner, S. T. Nguyen and R. S. Ruoff, Graphene-based composite materials, Nature, 2006, 442, 282-286.

23 D. A. Dougherty, Cation-pi interactions in chemistry and biology: a new view of benzene, Phe, Tyr, and Trp, Science, 1996, 271, 163.
24 T. Das and M. Karplus, Nuclear Quadrupole Interactions in Alkali Halide Molecules, J. Chem. Phys., 1965, 42, 2885-2891.

25 B. Roy, P. Bairi and A. K. Nandi, Supramolecular assembly of melamine and its derivatives: nanostructures to functional materials, RSC Adv., 2014, 4, 1708-1734.

26 T. Seki, S. Yagai, T. Karatsu and A. Kitamura, Formation of Supramolecular Polymers and Discrete Dimers of Perylene Bisimide Dyes Based on Melamine-Cyanurates HydrogenBonding Interactions, J. Org. Chem., 2008, 73, 3328-3335.

27 M. O. Sinnokrot, E. F. Valeev and C. D. Sherrill, Estimates of the ab initio limit for $\pi-\pi$ interactions: The benzene dimer, $J$. Am. Chem. Soc., 2002, 124, 10887-10893.

28 A. K. Geim, Graphene: status and prospects, Science, 2009, 324, 1530-1534.

29 K. S. Novoselov, A. K. Geim, S. V. Morozov, D. Jiang, Y. Zhang, S. V. Dubonos, I. V. Grigorieva and A. A. Firsov, Electric field effect in atomically thin carbon films, Science, 2004, 306, 666-669.

30 C. T. Seto and G. M. Whitesides, Molecular self-assembly through hydrogen bonding: supramolecular aggregates based on the cyanuric acid-melamine lattice, J. Am. Chem. Soc., 1993, 115, 905-916.

31 A. G. Bielejewska, C. E. Marjo, L. J. Prins, P. Timmerman, F. de Jong and D. N. Reinhoudt, Thermodynamic stabilities of linear and crinkled tapes and cyclic rosettes in melamine-cyanurate assemblies: A model description, $J$. Am. Chem. Soc., 2001, 123, 7518-7533.

32 U. Braun and B. Schartel, Flame Retardancy Mechanisms of Aluminium Phosphinate in Combination with Melamine Cyanurate in Glass-Fibre-Reinforced Poly (1,4-butylene terephthalate), Macromol. Mater. Eng., 2008, 293, 206-217.

33 A. Casu, G. Camino, M. De Giorgi, D. Flath, V. Morone and R. Zenoni, Fire-retardant mechanistic aspects of melamine cyanurate in polyamide copolymer, Polym. Degrad. Stab., 1997, 58, 297-302.

34 Y. Liu and Q. Wang, Melamine cyanuratemicroencapsulated red phosphorus flame retardant unreinforced and glass fiber reinforced polyamide 66, Polym. Degrad. Stab., 2006, 91, 3103-3109.

35 M. Modesti and A. Lorenzetti, Flame retardancy of polyisocyanurate-polyurethane foams: use of different charring agents, Polym. Degrad. Stab., 2002, 78, 341-347.

36 D. Q. Yi, M. Zhao and R. J. Yang, Melamine cyanuratemontmorillonite nano compound comprises melamine cyanurate and montmorillonite, in mass ratio of preset range, China Patent CN104829860-A, Aug. 12, 2015.

37 Y. Liu and Q. Wang, The investigation on the flame retardancy mechanism of nitrogen flame retardant melamine cyanurate in polyamide 6, J. Polym. Res., 2009, 16, 583-589.

38 X. Xu, Y. Ding, Z. Qian, F. Wang, B. Wen, H. Zhou, S. Zhang and M. Yang, Degradation of poly (ethylene terephthalate)/ clay nanocomposites during melt extrusion: effect of clay catalysis and chain extension, Polym. Degrad. Stab., 2009, 94, 113-123.

39 S. K. Sharma and S. K. Nayak, Surface modified clay/ polypropylene (PP) nanocomposites: Effect on physico- 
mechanical, thermal and morphological properties, Polym. Degrad. Stab., 2009, 94, 132-138.

40 O. I. Rovenskaya and G. Croce, Numerical simulation of gas flow in rough microchannels: hybrid kinetic-continuum approach versus Navier-Stokes, Microfluid. Nanofluid., 2016, 20, 1-15.
41 Y. Kojima, A. Usuki, M. Kawasumi, A. Okada, T. Kurauchi and O. Kamigaito, Synthesis of nylon 6-clay hybrid by montmorillonite intercalated with e-caprolactam, J. Polym. Sci., Part A: Polym. Chem., 1993, 31, 983-986. 